\title{
migroseopy tophy
}

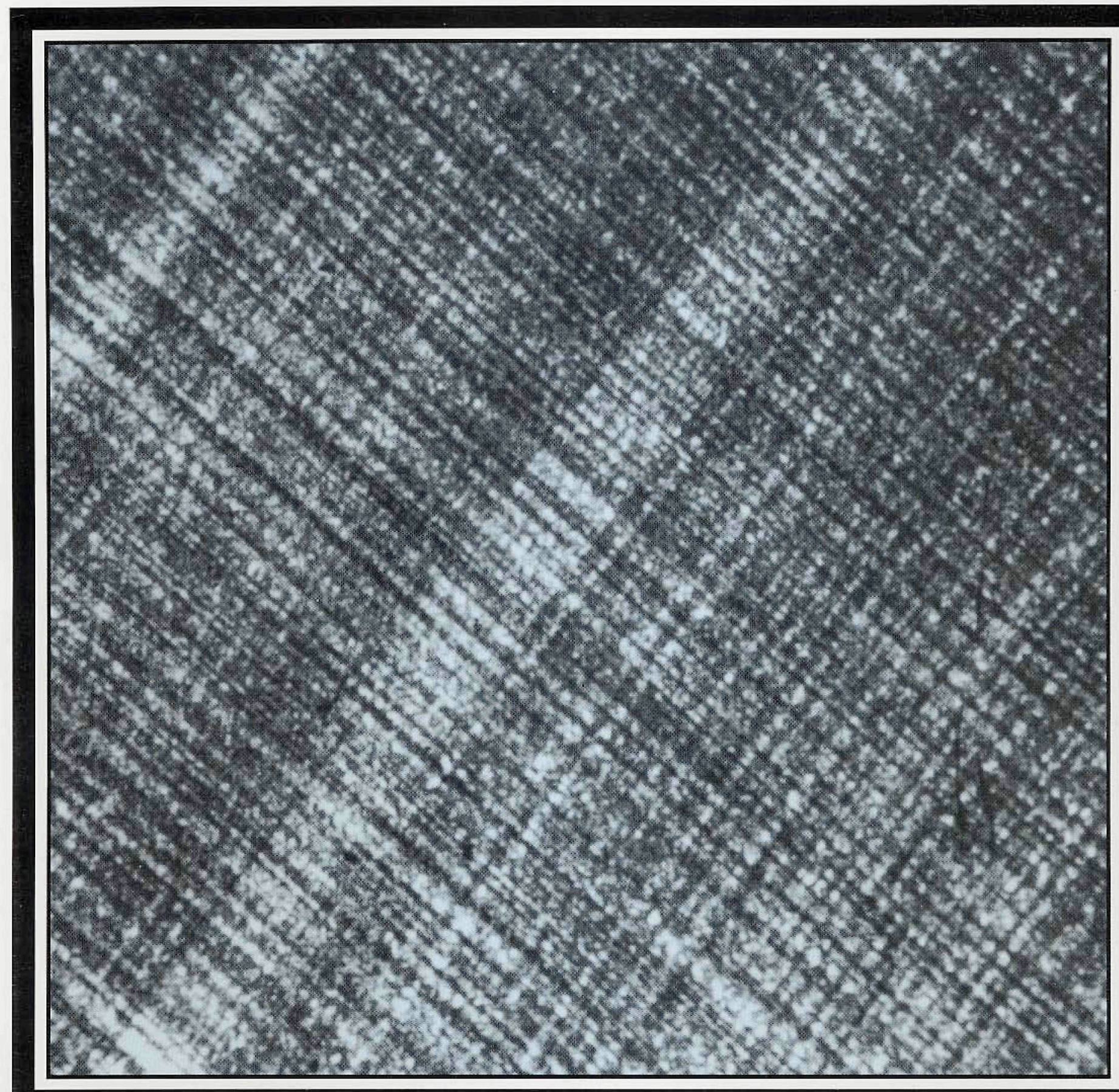




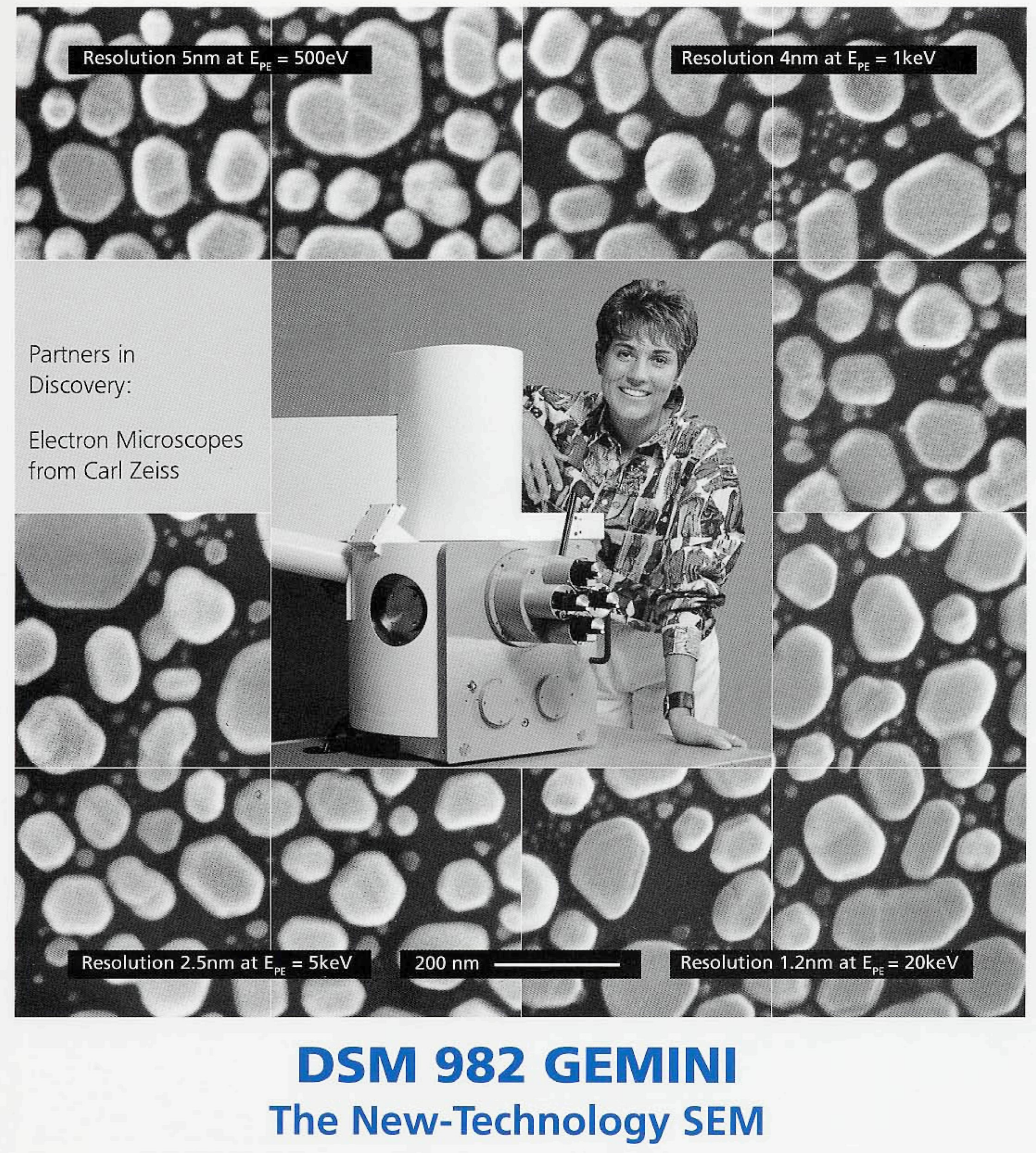

If you are looking for a field-emission scanning electron microscope with this outstanding resolution, with fully quantitative EDX-analysis capability at high take-off angle and with the potential to tilt your 6 inch sample

to $50^{\circ}$ at a working distance of only $6 \mathrm{~mm}$, then you should consider our revolutionary DSM 982 GEMINI. In any field of application your results will far exceed anything ever attainable before.

Carl Zeiss, Inc.

Electron Optics Division

Thornwood, NY 10594

Tel. (800) 3561090

Fax (914) 681-7443

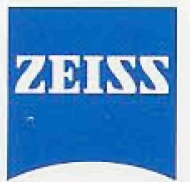

\section{Carl Zeiss}

Electron Optics Division

D-73446 Oberkochen

Germany

Tel.: (0 73 64) 20-27 00

Fax: (0 73 64) 20-45 30 